\title{
Los "fráxitos" de la disidencia sexual en la época de la globalización neoliberal
}

\section{Brad Epps (Universidad de Cambridge)}

\author{
“[E]l tan mentado 'sistema' no se sustenta solamente \\ por la fuerza de las armas ni por determinantes \\ económicos; exige la producción de cierto modelo de \\ sujeto 'normal' que lo soporte".
}

Perlongher, Néstor, Los devenires minoritarios, pp. 67-68.

"Muéstrame un homosexual feliz y te mostraré un cadáver sonriente".

Friedkin, William, Los chicos de la banda (1970 )

El deseo "minoritario", "alternativo" y "disidente" hace tiempo que está en crisis, no porque el orden establecido del mal llamado mundo occidental lo condene, persiga y anule, sino porque, con cada vez más regularidad, lo avala, protege y asimila. Esta, al menos, es la postura y la preocupación de un número considerable de críticos y activistas que configuran un reciente volumen coordinado por Dieter Ingenschay sobre sexualidades minoritarias en España y América Latina a fines del siglo XX y principios del siglo XXI. Dicho volumen, fruto de un encuentro celebrado en Berlín y publicado por Bibliotheca Ibero-Americana en 2018, constituirá el eje de mi intervención hoy, en gran parte porque reúne un amplio registro de perspectivas, todas articuladas en lengua española, de diversos países de América Latina y Europa. A través de una variedad de textos y contextos, subjetividades y situaciones, teorías y prácticas, estos críticos y activistas abordan, entre otras cosas, la disipación, disolución y discapacitación figurativas, si no reales, pero también la resistencia, rearticulación y reconfiguración, de una radicalidad antaño ligada de manera casi automática, "congénita" incluso, a la homosexualidad y a otras modalidades sexuales no abocadas a la reproducción - tanto biológica como simbólica- del sistema heteronormativo dominante. Conviene notar, de entrada, que la persistente vaguedad de términos tales como "orden establecido" y "sistema dominante" se soslaya solo parcialmente con el calificativo de "heteronormativo", no solo porque la aparente equivalencia entre heterosexualidad y normatividad es engañosa (como si toda práctica heterosexual fuera normativa), sino también, y sobre todo, porque el éxito de proyectos de reivindicación civil en un creciente número de países de ambos hemisferios ha generado una 
1. Véase, por ejemplo, el reciente volumen compilado por Lucas Martinelli, Fragmentos de lo Queer. Arte en América Latina e Iberoamérica.
2. Según Johnson, la radicalidad de la deconstrucción estriba en su cuestionamiento de la lógica de la oposición binaria, lógica que Johnson ilustra a través de una serie de pares normalmente incompatibles que in cluyen la objetividad y la subjetividad, la verdad y la falsedad, el habla y la escritura, el principio de placer y el principio de realidad, la conciencia principio de realidad, la conciencia
y la inconsciencia. Se trata de un y la inconsciencia. Se trata de un
cuestionamiento que se expresa, eiteradamente, en verbos tales como 'subvertir', 'minar', 'socavar', 'zapar', 'transgredir' y 'desestabilizar',

vo de sor

No es de sorprender, pues, que la estara a "conservadores" y "tradicionalistas" (los términos son de la propia Johnson), tanto de la derecha, obviamente, como de la izquierda. Para la autora, al igual que para Derrida, la relación con la izquierda era con todo, de co importancia especial, ya que ucía tendía a articularse de acuerdo con una lógica, o anti-lógica, progresista que se encontraría puesta contra las cuerdas cuando, en 1988, ochos años después de que Johnson publicara su artículo sobre el fracaso del éxito, salieran a la luz los escritos colaboracionistas colaboracionistas la Segunda Guerra Mundial. "homonormatividad" cuyos valores principales son la monogamia, el matrimonio y la familia -lo que Néstor Perlongher (1997: 56) llama la "conyugalización y sedentarización"-, así como el servicio militar, el individualismo, la competitividad y lucro económicos, el bienestar psicofísico (mente sana, cuerpo sano) y el atractivo corporal. Semejante concepto del "éxito", propio del capitalismo neoliberal, es visto y vivido por todo un conjunto de personas como un fracaso, si no total, al menos parcial. La precisión - si no total al menos parcial - es importante y remite a la preponderancia que se les concede a los desechos, fragmentos y restos. ${ }^{1}$ El propio Perlongher (1997: 73-74) declaró, a principios de los años ochenta, en medio de un clima dominado por los estragos del sida y la represión dictatorial, lo siguiente:

Sin rehusar dogmáticamente la importancia de la conquista de ciertos espacios jurídicos y legales, ni renegar de las experiencias vividas bajo el enunciado de la identificación, la crisis (o incluso la disolución) de estos movimientos [alternativos, disidentes, 'contraculturales'], además de indicar la extenuación de la estrategia identitaria, podría quizás propiciar (¿optimismo del análisis social?) una demanda de salida de los microcircuitos fagocitantes, una expansión extensa de las diferencias, no solo entre los propios 'minoritarios', sino abierta al campo social.

El inciso optimista de Perlongher -el "mismo" que sentenció en otro ensayo que el Frente de Liberación Homosexual en que había participado de manera fundacional constituía, "a todas luces, un fracaso" (1997: 83) - contrasta, sin embargo, con el pesimismo cultivado y el regodeo en la negatividad antisocial que caracteriza algunas de las obras más emblemáticas de la reciente teoría queer norteamericana - No al futuro, de Lee Edelman (2004); Optimismo cruel, de Lauren Berlant (2011); El arte queer del fracaso, de Judith, o Jack, Halberstam (2011) - producidas en un contexto no marcado ni por la represión dictatorial ni por los estragos del sida, sino por la consecución y la consolidación de una serie de derechos civiles y, lo que es más, por la concientización no solo de la "comunidad gay" (justo lo que Perlongher lamentaba que el Frente de Liberación Homosexual no hubiese conseguido), sino también del "conjunto del socius" (1997: 69), de nuevo en palabras de Perlongher. El fenómeno, por particular que pueda parecer, es harto general y de larga aunque accidentada duración: como bien dijera Barbara Johnson (1980) en relación con la institucionalización de la deconstrucción, también a principios de los ochenta: nada fracasa como el éxito. ${ }^{2}$

Dada la importancia del legado de la deconstrucción en lo que Fernando Blanco [inédito] designa como el proceso de "desandar los códigos binarios" del activismo y pensamiento crítico de la disidencia sexual, la referencia a Johnson no es nada casual. Informa no solo la voluntad de torcer y desmontar divisiones y jerarquías, sino también la preocupación por lo se podría llamar el "fráxito", neologismo con el cual pretendo designar menos una síntesis de 'fracaso' y 'éxito' que una tensa y oscilante hibridación "bastarda" - palabra, esta última, con la que Havelock Ellis calificara, a finales del siglo XIX, la entonces neológica "homosexualidad". Esta hibridación bastarda atraviesa aquellas propuestas, como la de Halberstam, que postulan encontrar en el fracaso un arte peculiarmente queer, propuesta harto debatida tanto por el éxito de Halberstam y la teoría queer en general, como por el hecho de que el fracaso fuera elogiado - como un "arte" necesario al éxito- por personas como Thomas Edison y Winston Churchill. Sea como fuere, la pregunta que Johnson se hace - “Cómo puede el impulso deconstructivo retener su energía crítica ante su propio éxito?" (1980: 7; Énfasis original) - es prácticamente la misma, mutatis mutandis, que se hacen estudiosos y estudiosas como Halberstam, Heather Love, José Muñoz, Judith Butler, Denilson Lopes y Lucas Martinelli: ¿Cómo puede el impulso alternativo LGBT y/o queer retener - o recuperar-su energía crítica ante su propio éxito? La ambivalencia entre la conjunción copulativa y disyuntiva "y/o" tampoco es casual, ya que si bien lo queer se ha promocionado como una opción recalcitrante a las 
políticas identitarias, su relación "de parentesco" con ellas es innegable. Es decir, su tan celebrada como vapuleada dedicación a la "desidentificación" - a un más allá o más acá de las categorías de la captación disciplinaria - se encuentra sombreada por aquello que pretende deshacer o, como diría Blanco [inédito], desandar, de modo tal que, en palabras de Martinelli, entre "las identidades rígidas (rigormortis) [...] queer ya es una más" (2016: 19). De ahí que se pueda hablar de "una genealogía gay/queer", tal y como lo hace Jorge Luis Peralta [inédito] en un perspicaz análisis de las novelas de Oscar Hermes Villordo. Dentro de esta genealogía gay/queer, cabría situar, pero solo en parte - es decir, solo de manera interseccional- una genealogía que, como recuerda Estrella Díaz Fernández [inédito], la crítica lesbiana también ha tratado de recuperar y visibilizar. Dicha genealogía no se limita, ni mucho menos, al quehacer literario en el que se enfocan Peralta y Díaz Fernández, sino que se extiende a toda una gama de manifestaciones socioculturales, entre las cuales están las artes visuales, el teatro, la música y, de modo especial, el activismo y la acción directa.

Lejos de ser una y unida, unívoca y unidireccional, se trata de una genealogía fragmentaria y dispersa, polívoca y multidireccional, de acuerdo con lo postulado por Michel Foucault, aunque no necesariamente con la meticulosidad gris y paciencia documentalista que elogiara el historiador francés. De hecho, tan fragmentaria, dispersa y desnaturalizada es esta genealogía que no es de extrañar que se preste a fracturas y escisiones de mayor magnitud, a formulaciones conjuntivas en las que prima lo disyuntivo sobre lo copulativo. Bernhard Chappuzeau [inédito], en una lectura del cine de Edgardo Cozarinsky, se refiere, por ejemplo, a "dos perspectivas opuestas" que configuran, entre ellas, una irónica reinscripción de pensamiento binario que, dicho sea de paso, el propio Perlongher asociaba con ciertas formas contraculturales y marginales del "negocio del deseo". ${ }^{3}$ Según Chappuzeau:

Por un lado se desarrolla la cultura gay como heredera del Gay Liberation Front después de 1969 y voz política para los derechos minoritarios, manteniendo un énfasis sobre los rasgos esenciales de la sexualidad en la formación de identidades y sus entornos sociales, y por el otro lado surge una oposición en la teoría queer, con cualidades más radicales de la disidencia y performatividad desestabilizadoras al crear cuerpos sin género en su rechazo unánime de las estructuras normalizadoras de sexualidad e identidad.

Lo gay, especialmente en cuanto "heredero" de un movimiento supuestamente "originado" en los Estados Unidos de América, constituye lo que el crítico español Fran Zurian llama un modelo de representación "positivo", que si bien se propaga por la televisión, también lo hace por medio de un vasto abanico de medios y modas.

Zurian estudia la presencia de personajes LGBTIQ en la televisión de ficción española de la "Transición" al gobierno de José Luis Rodríguez Zapatero, cuando, al igual que en otros países del mundo, se "avanzaron" versiones edulcoradas, sentimentaloides, asimilacionistas y consumistas no solo de lo gay y lésbico, sino también de lo queer -vocablo, me apresuro a señalar, cuya impronta anglófona, como veremos, no está en absoluto exenta de problemas . Estas versiones adecentadas y azucaradas se encuentran condicionadas, sin embargo, por otras amargas y acerbas que prevalecían como prácticamente las únicas posibles - al menos en grandes partes de la esfera pública-durante los años más duros del sida, aquellos en los que, justamente, las personas menos estadísticamente implicadas en el síndrome, las lesbianas, desempeñaron un papel crítico, ético y político fundamental. Es aquí, en relación con la historia del sida - que es también en parte la historia de la sexualidad posmoderna-y con los "fráxitos" de la disidencia sexual, donde habría que mencionar una relativamente nueva corriente crítica que cuestiona la proliferación de metáforas e ideas relacionadas con la disipación, la disolución, la discapacitación, la no futuridad y el
3. “Las relaciones de la prostitución viril están marcadas por una exacerbación de las diferencias. Diferencia de edad [...] Diferencia de clase [...] Las grandes oposiciones binarias que codifican el socius aparecen siendo ellas mismas deseadas; revelan así su reverso intensivo. Si el encuentro entre jóvenes y viejos remite a la vieja tradición occidental de la pederastia, se da también un peculiar cruce de clases, que se manifiesta entre algunos de los clientes como un deseo de salir de su
clifiesta entre algunos de los clase social" (Perlongher, 1997: 52). 
4. Es a este respecto que, si bien se abla del fracaso - 0 , si se quiere de la "discapacitación"-de la fuerza crítica de la disidencia sexual, también se puede hablar de modos de resistencia e insumisión que sin llegar a ser "exitosos" tampoco son, sin más, ilustraciones o pruebas del fracaso y de la no futuridad a ultranza.

5. Aunque el "mainstream gay globalizado" parece, en gran parte, ade in USA, la referencia al "imperio morteamericano" no debe congelarse en una delimitación falsamente tranquilizadora, como si "el problema"

se pudiera reducir a una determinada nación, por poderosa que sea. De hecho, al identificar "globalización"

y “americanización”, el propio Pierre

Bourdieu, en cuya obra se inspiran

Lawrenz y Zapata Galindo, no solo

refuerza la identificación de "ameri-

canización" y "norteamericanización"

-borrando así América Latina-, sino que también corre el riesgo de eximir de toda responsabilidad a Europa, Japón, Australia, Rusia, China, Arabia

Saudita y otras partes del mundoentre las cuales se encuentran aquellos reductos del poder adquisitivo en, por ejemplo, la Argentina y Colombia,

Senegal y Tailandia . En rigor, la noción de "reductos del poder adquisitivo" es válida para toda nación todo medida en que la nación-Estado se encuentra usurpada por la corporación multinacional o "posnacional” propia de la globalización. Esto no significa, claro está, que dichos reductos no se generalicen más en algunos países que en otros (de hecho, el concepto que en "clase hech" el concepto ende de semejante generalización del poder adquisitivo); ni que no sea importante fomentarlo que McRuer llama “afinidades transnacionales" (2016: 152); ni que Lawrenz y Zapata Galindo se equivoquen al arremeter contra el poderío de una nueva normatividad fabricada en el Norte y exportada, coactivamente, al Sur. Ahora bien, hasta qué punto esta "nueva normatividad" es importada por el Sur, $y$ hasta qué punto el Sur fabrica y/o renueva sus propias normatividades, y hasta qué punto "Norte" " "Sur" on entelequias ideológicas cuyaconson entelequias ideologicas cuya conceptualización binaria ningunea los "entre lugares" que Silviano Santiago (2000) propone como propios - 0 impropios- de una conceptualización más sutil, y más real, de la experiencia, son preguntas que, al menos en el ensayo citado, no se hacen. fracaso: a saber, la teoría "crip" o, si se quiere, la teoría tullida, contrapartida de la teoría "queer" o torcida. Robert McRuer, seguramente el teórico más influyente de la teoría tullida, en la entrevista incluida en el volumen analizado dice haber llegado a lo "crip" - de "cripple", palabra del inglés norteamericano originalmente peyorativa al igual que "queer" - por la crisis del sida (Moscoso Pérez y Arnau Ripollés, 2016: 150) y, por extensión, la crisis de la "liberación sexual". Si por un lado apunta a "la intersección de los estudios de la teoría queer con los estudios de las personas con diversidad funcional" (2016: 137), por otro lado afirma: "[y]a no basta con ser Queer para desafiar a los sistemas de poder, y muchos pensadores queer han señalado, por el contrario, que las identidades queer ahora contribuyen activa y abiertamente [con] los sistemas de poder" (2016: 142).

Esta "contribución" a los sistemas de poder, esta complicidad, no solo se ve en el énfasis en la ampliación del consumismo, el servicio militar, el matrimonio, y lo que Blanco llama el "romanticismo homoparental", sino también en el predomino de imágenes, altamente "rentables", de cuerpos sanos, jóvenes, fuertes y bellos en términos más bien clásicos y convencionales. Dicho pronto y mal, la teoría tullida denuncia, desde una postura que podría calificarse de "ectópica" respecto de la teoría torcida, una doble obligación compulsiva: la heterosexualidad, cuyos mecanismos de imposición y exigencia Adrienne Rich desmenuzó en 1980 en relación con la existencia lesbiana, y la capacidad y la salud tanto físicas como mentales. Lo "crip", al igual que lo "queer" (lo tullido, al igual que lo torcido), constituye, entonces, "una marca de fuerza, de orgullo y de desafío", según McRuer, "cuyas connotaciones negativas (relacionadas con el estigma y la burla) acarreará siempre" (2016: 138), al menos en principio. La salvedad, "al menos en principio" (o, mejor, "al menos en teoría"), es crucial, porque McRuer entiende estas cuestiones dentro de un contexto socioeconómico en el que el capitalismo neoliberal exacerba diferencias y ahonda brechas, pero también motiva alianzas de contestación internacional. A muchos respectos, la apuesta de Perlongher por un nuevo concepto de la belleza - y de la poesía - "mezclado con lo bestial, enchastrado, embarrado, pero lleno de brillos y de lujos" anticipa lo que Melania Moscoso Pérez y Soledad Arnau Ripollés, en su entrevista con McRuer, llaman la "re-apropiación de la dignidad disidente", dignidad que, evidentemente, no se deshace del todo ni de la indignidad ni de la indignación, en el sentido formulado por Stéphane Hessel, en contra del capitalismo financiero. ${ }^{4}$

Para Nina Lawrenz y Martha Zapata Galindo [inédito], el modelo de representación "positivo" examinado por Zurian en el contexto de la normalización de la homosexualidad en España ha llegado a ser tan contradictoriamente hegemónico en un creciente número de países que conforma, según ellas, un "mainstream gay globalizado".5

Esta nueva normatividad sexual surge de la promesa, aparentemente acomodaticia pero en realidad harto restrictiva, de que mediante el esfuerzo individual "cualquiera", sea cual sea su identidad genérico-sexual o étnico-racial o incluso su situación socioeconómica, puede "triunfar", puede lograr el "éxito", siempre entendido este en términos mercantilistas. Lawrenz y Zapata Galindo echan mano de las teorías de Pierre Bourdieu para afirmar que surgen "nuevas alianzas entre las fuerzas del mercado y un nuevo grupo de clientes", a saber, "una minoría privilegiada que se identifica 'solamente' con su identidad sexual". Se trata, en otras palabras, de la reconversión de una "comunidad" en principio diversa - no por idealizada siempre y solo irreal - en un "nicho de mercado" o de la reconversión de una "subcultura" - con toda la carga despectiva que comporta el término - en un "estilo de vida". Semejante estilización mercantilista genera, según Lawrenz y Zapata Galindo, "nuevos ideales del cuerpo y de la belleza que se ven influenciados por el aumento del consumo y las intervenciones de los medios" (1). Como bien saben, el impacto de estos "estándares de belleza y moda homogéneos" en clave gay dista mucho de ser "superficial", 
ya que se inscribe en cuerpos y comportamientos políticos y económicos. Es a este respecto que, junto con los "nichos de mercado" y "estilos de vida", emergen y se consolidan grupos de presión, los llamados lobbies gay, que señalan tanto Fernando Blanco como Alfredo Martínez-Expósito [inédito], entre otros. Estos lobbies, como el nombre indica, se apartan del activismo callejero y, desde luego, de toda actuación calificable de hedonista, promiscua y antisocial, para "adecentarse" y así adentrarse en los vestíbulos y despachos del poder político institucional. Son, en definitiva, sintomáticos del deslizamiento de la norma, de su paradójica (des)naturalización instrumentalista, de su "fráxito".

Fernando Blanco, en una brillante lectura del pornoactivismo en el Chile posdictatorial, examina, justamente, “[1] a reapropiación por parte de la derecha y [...] del gobierno de la Nueva Mayoría de las discusiones ciudadanas en torno a identidad de género e identidad sexual defendidas en el pasado por sectores cercanos a la izquierda histórica popular". Sin negar los logros en la esfera legislativa en Chile y otros países de América Latina, especialmente en la Argentina, Brasil, Uruguay, México y Colombia, Blanco sondea las contradicciones y retos que el "paradigma normalizador" y el "modelo optimista de reparación" acarrean en la época de la globalización neoliberal. Al igual que Martínez-Expósito, quien reconoce que “[e]l proceso de normalización es [...] en cierto modo un proceso de disolución de la especificidad cultural LGBTQ y su inherente queerness", Blanco se detiene en unas actividades y actuaciones que "luchan en contra del menú liberal de orientaciones y gustos impuestos por el liberalismo económico y político". Una figura emblemática de dicha lucha es el recién fallecido Pedro Lemebel, según Dieter Ingenschay [inédito] "la voz más aguda" de la resistencia contra la imposición del modelo único economicista en el ámbito de las sexualidades disidentes. Para Lawrenz y Zapata Galindo, "Lemebel desarrolla un discurso queer alternativo a través de su llamada low queer art" y manifiesta "su disgusto en el gusto del mainstream neoliberal". Tanto el discurso como el disgusto los desarrolla y manifiesta a través de su propia persona, carnal y deslenguada, "[f] araónica, monumental [y] desafiante", para usar las palabras de Blanco. El desafío de Lemebel, siempre provocativo, se extiende a la monumentalización de una historia hegemónica en la que una revuelta en un bar gay en un barrio de la Ciudad de Nueva York se erige como el origen y punto de referencia obligatorio de todo un movimiento de reivindicación socio-sexual.

En una de las crónicas de Loco afán, titulada "Crónicas de Nueva York (El Bar Stonewall)", Lemebel se mofa de "estas gringas militantes tan beatas y comerciantes con su historia política" (2000: 70) y se estremece, en una mezcla de desdén, temor y voluptuosidad vomitiva, ante los "músculos y físicoculturistas" cuya "potencia masculina [...] te empequeñece como una mosquita latina" (2000: 71). En términos que a la vez recuerdan y matizan los de la teoría tullida, aduce una "desnutrición de loca tercermundista" (2000: 71) que pone sobre el tapete el hambre, la escasez y la pobreza como factores de "discapacitación". Finalmente, en relación con la bandera de "todos los colores del arco-iris gay", pone en tela de juicio su validez policromada al sugerir que el estandarte sea, a fin de cuentas, de un solo color, el blanco, "[p]orque tal vez lo gay es blanco" (2000: 71). La percepción y crítica de una blancura preponderante en la promoción a escala global de lo gay funciona a la vez como una tónica y un revulsivo en el suministro de un proyecto centrado en la expansión más que en la deconstrucción de la normatividad. Como una loca consagrada a la desacralización, Lemebel, hondamente influido por Perlongher, defiende una especie de anormalidad contrahegemónica en la que cuestiones de raza, etnicidad y clase, pero también de edad, apariencia física y estado de salud —o enfermedad- son indisociables de cuestiones de género y sexualidad que solo parcialmente podrían considerarse como fundamentales. ${ }^{6}$ Ahora bien, es precisamente en la apuesta por la volatilización de todo fundamento y toda esencia que lo queer pretende apartarse de lo gay, lésbico e
6. En su propensión al cuestionamiento polifacético, a la práctica interseccional, el artista de carne y hueso que fue Lemebel guarda una afinidad con más de un personaje de ficción, entre ellos, "Cleopatra la travesti y sacerdotisa milagrera" que protagoniza La Virgen Cabeza, de Gabriela Cabezón Cámara, primera novela de una trilogía posdictatorial que estudia Guadalupe Maradei [inédito]. Al precisar que el vocablo 'cabeza' deriva, en el contexto popular rioplatense, de 'cabecita negra', locución que designa a los migrantes de ascendencia indígena, Maradei demuestra el potencial político de la etimología, cuyos vericuetos pueden ser tan fragmentarios y dispersos como los de la genealogía. También indica cómo la resemantización - tan cara a la suerte del término y concepto 'queer'- puede tener y concepto 'queer'- puede tener
resonancias étnicas, raciales y económicas que con demasiada frecuencia quedan amortiguadas, cuando no silenciadas, bajo un vocabulario más expresamente genérico-sexual. La "corporalidad travesti generizada, racializada [y] subalternizada" que marca, según Maradei, la novela de Cabezón Cámara apunta a prácticas y performances extranovelísticas y, lo que es más, a una dinámica de trasvase mediante la cual los hechos más presuntamente naturales se presentan como ficciones "fundacionales", es decir, como relatos “esencialmente" ideológicos. 
7. La cuestión de la lengua, que oscila entre lo carnal y lo simbólico, es, como he insistido en más de un trabajo, tan resbaladiza como significativa. En un ensayo de 1967 sobre Mariano José de Larra incluido sobre Mariano José de Larra incluido declaró: “la negación de un sistema intelectualmente opresor comienza necesariamente con la negación de su estructura semántica" (32, n. 2). A casi cincuenta años de distancia, la declaración de Goytisolo pustancia, la tar excesivamente confianzuda, hasta idealista, pero no deja de señalar la importancia de las palabras en la ordenación de las cosas, los cuerpos y la materialidad en general. Judith Butler, en muchos aspectos tan diferente de Goytisolo también da testimonio de a tensión entre el discurso lingülsti

la y la materialidad corporal: después de Gender Trouble (1990), traducido al español como El género en disputa, responde a las críticas de que no había atendido lo suficientemente a cuestiones de materialidad históricocorporal con Bodies that Matter: On corporal con Bodies that Matter: $O$ ex" (1993), cuya traducción al español, Cuerpos que importan. Sobre los límites materiales y discursivos del 'sexo', no capta el juego discursivo-materialista del término "matter" (que significa tanto 'importar' como 'materia', relaciona'da, éta última palebra, relaciona'madre') introduce, con 'matriz' ' 'madre') e introduce, seguramente sin quererlo, un juego con el término 'importar' que, como ya hemos visto, sugiere transacciones internacionales, es decir, exportaciones e importaciones, poco o nada equitativas. incluso trans, volcados, al menos en su formulación contradictoriamente mayoritaria, a la estabilización de identidades, subjetividades, comunidades y proyectos políticos.

Si lo queer funciona como la contrapartida díscola y excesiva de lo gay, lo hace, sin embargo, en muy menor grado respecto de lo lésbico, trans- e intersexual. De hecho, en diversos trabajos que versan explícitamente sobre modalidades lésbicas y/o transgenéricas, el término "queer" ni se menciona. Es decir, evitan, ignoran y/o desestiman la contienda terminológica y conceptual gay-queer y se concentran en otras. Díaz Fernández, por ejemplo, examina, dentro de un lábil marco genealógico lésbico, la significación del nombre propio, del pseudónimo y del anónimo; Rafael Mérida Jiménez [inédito] propone, dentro de un no menos lábil ámbito genealógico transgenérico, una "transtextualidad" que abarca la gestualidad, la sexualidad y la teatralidad; Elena Madrigal, por su parte, se adentra en lo que designa como el "universo literario zapoteco" en el que la transcripción, la traducción y sus límites confluyen en procesos de resistencia indígena. La diversidad sociosexual que apoya y avanza Madrigal [inédito] implica una diversidad sociolingüística que supera la contienda LGBTQ y en la que términos como "muxe" y "ngiu'u" figuran de manera destacada. La traducción de estos y otros vocablos, pertenecientes a lenguas indígenas pero también al español en todas sus variantes (variación en que insistía Perlongher), no solo corre el riesgo tradicional de "traicionarlos", sino también de borrarlos en aras de un puñado de términos y conceptos de procedencia anglófona y, en menor grado, francófona (a saber, "gay" y "queer"). Es a este respecto que Fernando Blanco tiene razón al notar la importancia de "la autorreflexión sobre los propios lenguajes y discursos 'en los que y con los que' se aborda el desafío de sostener la diferencia sexual en lo público y lo simbólico renuente a la normalización liberal". Gran parte del desafío estriba, seguramente, en la omnipresencia, en los estudios y debates sobre "sexualidades alternativas", de términos tales como "mainstream", "performance" y los ya ampliamente mentados "gay", "queer" e incluso "crip" - palabras que, como he dicho en otro ensayo, no tienen calle o historia fuera de ámbitos angloparlantes y, como apunta Martinelli, "[n]o nos incomoda[n]" (2016: 18). La atención que Madrigal dedica a personas y personajes sexodiversos es extensiva, pues, a personas y personajes lingüidiversos.?

"Nombrar siempre es un peligro", observa el crítico brasileño Denilson Lopes, para quien "[1]a utilización de queer sigue siendo algo restringido a los circuitos académicos" y para quien "la falta de traducción lingüística podría bien ser un indicio de [una] falta de traducción intelectual" (2016: 27). La diversidad lingüístico-cultural difícilmente puede contentarse con la consolidación de "queer" como signo privilegiado de la contestación política. De ahí que Lawrenz y Zapata Galindo hablen de la necesidad de reconocer y criticar "una norma queer global(izada) en el 'Norte", ligada al homonacionalismo cripto-occidental y, lo que es más, al "blanqueamiento rosa", tal y como han polemizado Jasbir Puar y Joseph Massad en el terreno del conflicto entre Israel y Palestina, en el que Israel se presenta, a través de su política sexual, como más "democrático" y "tolerante" que sus adversarios; de ahí, también, que Lawrenz y Zapata Galindo, entre muchos otros, insistan en la necesidad de avanzar un "queer alternativo". Un queer alternativo a lo queer globalizado sugiere, desde luego, un proceso de desplazamiento y de torcimiento, un rizar el rizo, que recuerda la imbricación movediza de la norma, en cuanto límite, y de la transgresión señalada por Foucault (1963) en su ensayo sobre Georges Bataille, "Prefacio a la Transgresión". También sugiere una "revolución permanente" que se moviliza en contra de la permanencia, es decir, de su propia consolidación, institucionalización y normalización. Esta "revolución permanente" no ha obstado para que algunos de los "valores consagrados" de la teoría queer angloamericana, como Eve Kosofsky Sedgwick y Lee Edelman, intentaran erigir y estilizar lo queer como la figura y la forma de una política alternativa e incluso, en el caso de Edelman, de una negatividad radical que se cifra en la denuncia de toda "futuridad reproductiva". 
Llama la atención que la negatividad radical a la que Edelman se aferra apenas se detiene en cuestiones de clase, raza, etnicidad, religión, nacionalidad, capacitación, colonialidad, historia y lengua -más allá de unos juegos retóricos dentro de un inglés nunca cuestionado como vehículo privilegiado de lo queer. Dicho de modo más directo, Edelman monumentaliza y totaliza un queer que al carecer de otros rasgos acaba pareciendo tan blanco, tan gringo, como la bandera de "todos los colores del arco-iris gay" que critica Lemebel. La historia misma parece, en manos de Edelman, prácticamente vaciada de contenido geopolítico como no sea el norteamericano. De hecho, lejos de eludir toda captación definicional, lo queer, para Edelman, se define, como observa Halberstam, como la muerte y la finitud (Halberstam, 2011: 106). Es importante notar que Edelman, en su afán de perfilar lo queer como una negatividad ejemplar, deja de lado otras formulaciones, otras realidades, que también podrían relacionarse con la no futuridad: a saber, la marginación, explotación y destrucción económicas, la depredación neocolonial, la extrema discapacitación y la enfermedad, y un largo etcétera. Sin ir más lejos que los Estados Unidos, país que constituye el casi exclusivo marco de referencias de Edelman, si hay un grupo de "sujetos" que encarnan y emblematizan la no futuridad, bien podrían ser los hombres negros, sea cual fuera su "orientación sexual", ya que su esperanza de vida es, estadísticamente hablando, una de las más bajas del país. Algo parecido puede decirse de muchos "discapacitados" y enfermos para quienes, en la opinión de Merri Lisa Johnson (2015), "la retórica del fracaso" tiene unas implicaciones demasiado literales para que pueda estilizarse como un arte deseante y hasta deseable.

Es a este respecto que me atrevería a "desencializar" lo queer al desligarlo, al menos en parte, de las relaciones entre personas del "mismo" sexo, que atraviesa la obra de Edelman y, de modo distinto, la de Halberstam, quien califica de "decididamente “unqueer"' (2011: 90) la novela Trainspotting, del escocés Irvine Welsh, a pesar de centrarse esta en un grupo de jóvenes marginados enganchados a la heroína y "sin futuro". Si bien encuentra en Trainspotting muchos de los atributos asociados con lo queer, entre los cuales están el fracaso y una crítica feroz de la "vida normal", Halberstam encuentra la novela "demasiado hetero-masculina" (2011:92) como para merecer - que valga el término-inclusión en el oscuro panteón de lo queer. Sin descartar del todo su argumento, que ve en la homofobia la descalificación de lo queer, cabe cuestionar si la homofobia de los marginados, los pobres y los discapacitados es la misma que la de los poderosos, con frecuencia perfumada con una tolerancia que Herbert Marcuse llamara "represiva". La pregunta que formula Néstor Perlongher en su ensayo "Matan a una marica", “¿De qué se habla cuando se habla de violencia?" (1997:36) se presta, entonces, a otra: ¿de qué se habla cuando se habla de homofobia? A Perlongher, la cuestión de la violencia, y más específicamente la violencia ejercida contra los homosexuales, lo lleva a preguntarse: “¿Cuáles son las fuerzas en choque, cuál el campo de fuerzas que afecta su entrechoque?" (1997: 37). A diferencia de Halberstam, para quien lo "unqueer", sobre la base de una excesiva carga "heteromasculina" y de una "simple inversión de la autoridad masculina" (2011:92), parece demarcarse claramente de lo "queer", Perlongher atiende a las oscuras imbricaciones entre órganos y cuerpos - y no solo sujetos identitarios - que hacen que entre "toda la gama de vividores, lúmpenes, desterrados, fugados o simplemente confundidos, pasajeros en tránsito por las delicias del infierno, suel[a]n recultarse los propios ejecutores de maricas" (2011:39).

En otro ensayo, "Avatares de los muchachos de la noche", Perlongher insiste en la existencia de "cierta relación de contigüidad entre las marginalidades sexuales (que atentan contra el orden de la reproducción sexual) y económicas (que atentan contra el orden la producción social); lazo entre homosexualidad y marginalidad que se mantiene vigente a despecho de los reclamos de la dignidad de los homosexuales más modernizados" (1997: 47). Es decir, lejos de trazar una línea divisoria entre, por 
8. Es interesante notar que McRuer, quien reconoce que tanto la comunidad LGBT como la de los discapacitados tiene sentidos de identidad y orgullo harto definidos, se interesa por aquellos lugares, caminos y contactos en los que no se dé por sentado que una persona x, y o $z$ " y en los que "incluso puede haber sospechas acerca de la inclusión de aquella persona" en una comunidad determinada (Moscoso Pérez y Arnau Ripollés, 2016: 151). ejemplo, drogadictos machistas y maricas promiscuas, Perlongher habla en términos de redes y enredos, cruces y entrecruces, flujos y derivas. Anticipa y, en muchos aspectos ahonda, pues, lo que luego se presentaría, desde el Norte, como la radicalidad "queer", declarando: "[e]s preciso evitar la tentación de pensar [los personajes de esta red de tránsitos] en tanto 'identidades', para verlos en cambio como puntos de calcificación de las redes de flujo (de las trayectorias y los devenires del margen)" (1997: 47). Consciente de los peligros de una formulación excesivamente teórica, precisa que estas redes y relaciones "no se limita[n] al plano abstracto sino que se denota[n] en las solidaridades prácticas que se establecen entre los diversos marginales" (1997: 47). Mediante la referencia a las "solidaridades prácticas", en medio de un discurso más característico del aula que de la calle, Perlongher deja abierta, en el sentido de irresuelta, una problemática que Halberstam parece clausurar. Dicha problemática también acarrea todo un reto: el de no conceder a los poderes fácticos, sin más, esa "mano de obra" hetero-masculina homófoba y racista -Perlongher habla de "microfascismos"- que constituye "la base militante" de políticos reaccionarios a lo largo del mundo. En términos más polémicos, lo queer-y el reto radical que presuntamente encierra - no abarca solo a la loca, sino también al marginado, al "delincuente" que la agrede, situación admirablemente descrita por Lemebel (2000) en una crónica de La esquina es mi corazón, "Las amapolas también tienen espinas", que guarda una relación tanto temática como retórica con "Matan a una marica", de Perlongher.8

Dieter Ingenschay [inédito], el editor de muchos de los ensayos en lengua española que he estado citando, ofrece -en un artículo sobre la memoria gay en las transiciones políticas de España, la Argentina y Chile - una interesante vuelta de tuerca a la curiosa totalización y negación de tiempos y sujetos que marca la obra de Edelman, Leo Bersani y otros paladines del llamado "giro antisocial". Ingenschay reconoce que no hay "uniformidad, sino tensiones y discusiones dentro de las respectivas naciones" y que las transiciones y rupturas, formulaciones del fracaso y de la no futuridad, pueden variar considerablemente de país en país, de región en región, de poblado en poblado, de barrio en barrio y, cómo no, de persona en persona. Reconoce, además, que "el gran tema de la cultura de la memoria", inevitablemente involucrado en concepciones de futuridad y fracaso, es de una importancia especial en aquellos países que han experimentado regímenes dictatoriales y desapariciones masivas. Afirma, en resumen, que la violencia - del orden político y económico, dentro y fuera de determinados países - "no es una cuestión particularmente gay" - o queer-aunque tampoco es una cuestión particularmente heterosexual. Tanto es así que, en estas y otras partes del mundo en las que lo simbólico y lo real se articulan y desarticulan en otras lenguas, y en las que otros pasados y presentes informan y deforman otros futuros, el verdadero "queer alternativo" consistiría en la diversificación y dispersión, tal vez incluso en la suspensión si no supresión, de este vocablo clave, demasiado clave.

Es importante aclarar, de todos modos, que la presencia de términos y conceptos procedentes del inglés como "queer" no constituye en sí un problema insoslayable. Después de todo, la importación, la imitación y la apropiación son prácticas que gozan de una larga y variada tradición dentro de la cultura sexual minoritaria y alternativa. Dicha apropiación constituye lo que Alberto Mira [inédito] designa como una "estrategia" que ayuda a "fortalecer (discursivamente) las identidades homosexuales", pero no de modo perenne y permanente, ya que "[l]a apropiación no establece verdades, sino que produce un discurso provisional, provocativo, encaminado a conseguir unos fines" (citado en Ramos Rebollo) que, una vez "conseguidos", pronto pueden abrirse a otros. La referencia a un discurso provisional en relación con el fortalecimiento de las identidades es importante en la medida en que introduce una provisionalidad estratégica, o quizás solo táctica, frente al ya más familiar esencialismo estratégico dentro de lo que podría llamarse - y de hecho, se ha llamado- una cultura o comunidad. 
Es aquí donde el discurso provisional - un decir dado, al menos en parte, al desdecirse liga a la comunidad efímera que Marta Segarra [inédito] pondera en un bello ensayo sobre la poesía de Maria Mercè Marçal, "la escritora lesbiana pionera y emblemática en la literatura catalana". A través de la textura poética de Marçal, Segarra elucida una preocupación que comparte en mayor o menor grado un número importante de pensadores y activistas, a saber: la comunidad. Lejos de reafirmar una estructura de mera oposicionalidad, Segarra aboga por una teoría y práctica de "la comunidad no como una afirmación de determinadas características o propiedades que nos reunirían con otros individuos semejantes (por ejemplo, ser catalán, pero también ser mujer, o lesbiana...), sino como una 'expropiación' de nosotros mismos, es decir, no como algo que vendría a 'colmar' la brecha que existe entre los individuos, sino como aquello que se sitúa en este vacío, en el 'entre"'. Este "entre" difícilmente se deja cuajar como "pura negatividad" ni tampoco, obviamente, como pura positividad. Más bien, señala el espacio y el tiempo promiscuos de la mixtura, la diferencia y la interseccionalidad que promueven Lawrenz y Galindo Zapata, para quienes la disidencia sexual y las sexualidades minoritarias no se pueden desligar de "todas las categorías de desigualdad social", categorías que incluyen, de modo tan insistente como difícil, a esos mismos "marginados hetero-masculinos" que Halberstam califica de "decididamente "unqueer". El "entre" -que para Perlongher es donde "entra" un "devenir" que "no va de un punto a otro" (1997: 68) - señala, en fin, la mutabilidad y hasta la reversibilidad - siempre coyunturales y situadas - del fracaso y del éxito, el "fráxito" pues, porque si los logros y avances en el ámbito de los derechos civiles pueden significar el fracaso y la "discapacitación" de la disidencia más radical, este mismo fracaso, esta misma "discapacitación", puede significar un éxito a contrapelo, sean cuales sean los términos, siglas o lenguas que se empleen. 


\section{Q Bibliografía}

» Berlant, Laurent. Cruel optimism, Duke University Press, 2011

"Dieter Ingenschay (ed.) Eventos del deseo. Sexualidades minoritarias en las culturas-literaturas de España y Latinoamérica a fines del siglo XX. Berlín, Bibliotheca Ibero-Americana, 2018

» Edelman, L. (2004). No Future: Queer Theory and the Death Drive. Durham, Duke University Press.

» Foucault, M. (1963). Préface à la transgression. En Critique, 195-196, pp. 751-770.

» Halberstam, J. (2011). The Queer Art of Failure. Durham, Duke University Press.

»Johnson, B. (1980). Nothing Fails Like Success. En SCE Reports, 8, pp. 7-16.

» Johnson, M. L. (2015). Bad Romance: A Crip Feminist Critique of Queer Failure. En Hypatia, 30.1, pp. 251-267.

"Lemebel, P. (2000). Crónicas de Nueva York (El Bar Stonewall). En Loco afán: Crónicas de sidario , pp. 70-72. Barcelona, Anagrama.

"Lopes, D. (2016). Por una nueva invisibilidad. En Martinelli, L. (comp.). Fragmentos de lo queer. Arte en América Latina e Iberoamérica, pp. 27-40. Buenos Aires, Editorial de la Facultad de Filosofía y Letras, Universidad de Buenos Aires.

» Martinelli, L. (2016) Fragmentos de lo queer. Arte en América Latina e Iberoamérica. En Martinelli, L. (comp.). Fragmentos de lo queer. Arte en América Latina e Iberoamérica, pp. 17-25. Buenos Aires, Editorial de la Facultad de Filosofía y Letras, Universidad de Buenos Aires.

" Moscoso Pérez, M. y Arnau Ripollés, S. (2016). Lo queer y lo crip, como formas de re-apropiación de la dignidad disidente: Una conversación con Robert McRuer. En Dilemata 8.20, pp. 137-144.

»Peers, D., Brittain, M. y McRuer, R. (2012). Crip Excess, Art, and Politics: A Conversation with Robert McRuer. En The Review of Education, Pedagogy, and Cultural Studies, 34, pp. 148-155.

»Perlongher, N. (1997). Prosa plebeya: Ensayos 1980-1992. Buenos Aires, Colihue,.

»Rich, Adrienne. Compulsory Heterosexualiity and Lesbian Existence. London, Only Women Press, 1981

"Santiago, S. (200o). O entre-lugar do discurso latino-americano. En Uma literatura nos Trópicos: Ensaios sobre dependência cultural, pp. 9-26. Río de Janiero, Rocco. 